\title{
Anomalous behaviour within a systematic series of barium sulfate growth modifiers
}

\author{
F. Jones, J. Clegg, A. Oliveira, A. L. Rohl*, M. I. Ogden, G. M. Parkinson, A. M. Fogg, M. M. Reyhani. \\ AJ Parker Co-operative Research Centre for Hydrometallurgy, School of Applied Chemistry, Curtin University of Technology, GPO Box U1987, Perth WA 6845 Australia.
}

a.rohl@curtin.edu.au

Phone (618) 92667317 Fax: (618) 92662300

Received (in Cambridge, UK) xst xxxx 2001, Accepted xst xxxx 2001

First published as an Advance Article on the web xst xxxx 2001

\begin{abstract}
The generally accepted view that phosphonate derivatives are more potent than the analogous carboxylates as crystal growth modifiers for barium sulfate was systematically studied by using trifunctional molecules varying from the triphosphonate through to the analogous tricarboxylate; the results suggest that predictions based on simple structural features should be made with caution.
\end{abstract}

Control of particle morphology is a desired feature in many industrial applications ${ }^{1-3}$. Much research has focussed on being able to 'tailor-make' or design additives which affect particle morphology in a predicted way ${ }^{4,5}$. Barium sulfate has often been used as a model compound since it is easy to control the precipitating conditions and it is an industrially important scale forming compound. Previous investigations have been conducted which assess a systematic series of molecules ${ }^{6-13}$ in an effort to relate crystallization inhibition to molecular structure. In these cases, such work has involved varying the structure of a molecule containing varying numbers of a specific functional group. Our approach has been to substitute one functional group with another. This minimises changes in the overall additive structure.

It was found by Black et al. ${ }^{7}$ that at least two phosphonate groups are required for inhibition (with a 3 atom chain between the phosphonate groups) and that small carboxylate molecules are ineffective as inhibitors and/or morphology modifiers ${ }^{7}$ (polymers such as polyacrylates are of course used commercially as scale inhibitors since the relatively weak carboxylate-crystal surface interaction is more than compensated for by the large number of interactions available ${ }^{14}$ ). Very recently, however, aminocarboxylates have been shown to have an effect on barium sulfate morphology ${ }^{15}$. These experiments were conducted at very high pHs (10-12) and at high carboxylate to barium ratios resulting in chelation of the barium in solution, which could explain why their results differ from those of Black et al. ${ }^{7}$

The effect of chain length was studied by Bromley et al. ${ }^{6}$, where a series of tetraphosphonate molecules of differing carbon chain length (6-11 carbons) was investigated where two methylenephosphonate molecules were attached via a nitrilo group to the carbon chain at each end. The greatest inhibition occurred when the link between the two sets of phosphonate groups was greater than $6 \AA$ and allowed at least two of the four phosphonate groups on the molecule to adsorb onto the surface in place of sulfate groups. Thus, although greater than two phosphonates are present on the organic molecule, adsorption is assumed to require only two of these groups. Using these principles, inhibitors have been designed and shown to be effective $^{6,9,16}$.

We decided to test these conclusions by systematically altering the functional group in a series of molecules with a consistent structural framework. Thus, we set out to investigate the inhibiting efficacy of a molecule containing a decreasing number of phosphonate groups which are replaced by carboxylic acid groups. In this study both morphology of the resultant particles and the kinetics of crystallization were assessed.

The following organics were investigated: NTMP = nitrilotrimethylenephosphonic acid, NTA $=$ nitrilotriacetic acid, NDMPA = nitrilo(acetic acid)di(methylenephosphonic acid), NMPDA $=$ nitrilo(diacetic acid)(methylene phosphonic acid). The structures of this series of molecules are given in Figure 1.

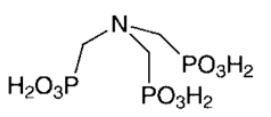

NTMP

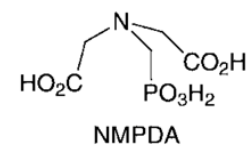

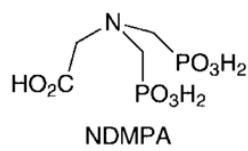

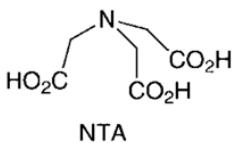

Figure 1. Molecular structure of the organics investigated in this study.

It was anticipated that the efficacy of the additives would decrease as the number of phosphonate groups in the additive decreased. A study of calcium carbonate crystallization, using the $\mathrm{pH}$-stat method $^{17}$ as implemented by Wheeler et al., ${ }^{18}$ supported this expectation, with the levels of additive required to achieve $90 \%$ inhibition of growth being: NTMP, $0.0001 \mathrm{mM}$; NDMPA, 0.0003 $\mathrm{mM}$; NMPDA, $0.001 \mathrm{mM}$; NTA, $0.01 \mathrm{mM}$ (details of this work will be reported elsewhere).

For the barium sulfate studies, the procedure consisted of monitoring crystallization using conductivity and then filtering the particles for SEM preparation. A stiochiometric amount of sodium sulfate was added to barium chloride solution such that the final concentration was $0.25 \mathrm{mM}$. The temperature was $25^{\circ} \mathrm{C}$, the $\mathrm{pH}$ was 5.6 for all experiments and the resulting supersaturation ratio was 25 . The standard conditions result in rectangular crystals (Figure 2a). The additive was added at concentrations ranging from $0.007 \mathrm{mM}$ to $0.078 \mathrm{mM}$ to the barium chloride solution prior to the sodium sulfate being added to start precipitation.

As the concentration of NTMP is increased, inhibition increases and the particles of $\mathrm{BaSO}_{4}$ become rounder and thinner (Figure $2 b$ ). At $0.017 \mathrm{mM}$ the observed rate of de-supersaturation is half of the control. At this concentration, 1 NTMP molecule exists per 15 barium atoms or 1 phosphonate functional group per 5 barium ions. 
The NDMPA showed little to no effect on the kinetics of barium sulfate precipitation, but did show an effect on the morphology at $\leq 0.042 \mathrm{mM}$. The morphology of the barium sulfate obtained in the presence of this organic was rounded, elliptical shaped platelets (Figure 2c).

The NMPDA molecule has no effect on the de-supersaturation rate or on the morphology of the resultant barium sulfate under the conditions studied (Figure 2d).

Surprisingly, the NTA molecule does show inhibition of barium sulfate precipitation but only at much higher concentrations than that used for the triphosphonate. The concentration of NTA required to reduce the de-supersaturation rate by half is 0.078 $\mathrm{mM}$, which is equivalent to 1 NTA molecule per 3 barium ions. That is, on a carboxylate to barium atom ratio, it is $1: 1$. Thus, the NTMP is a much more efficient inhibitor than NTA. While it is possible that the inhibition observed is due to solution complexation of barium cations, there is, however, a noticeable effect on the morphology of the barium sulfate obtained in the presence of NTA even at low concentrations. For comparison, the carboxylate/Ba ratio used by Uchida et al. ${ }^{15}$, is $6: 1$ in the case of NTA. In our study the morphology changes begin to be observed at ratios of approximately 1:5 (carboxylate/Ba). Additionally, the complexation constants of all the molecules investigated in this work are of the same order*19 so while NTA could complex barium in solution this factor should be approximately constant for all the additives studied in this work. As the concentration of NTA is increased, the particles become increasingly smaller and rounder (Figure 2e and 2f).

As a growth inhibitor, the NTA molecule outperformed both the mono and di-phosphonate containing molecule at the same concentrations suggesting that the mode of interaction in the case of NTA is different

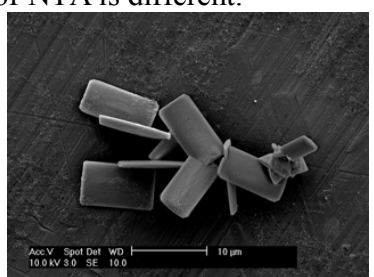

a)

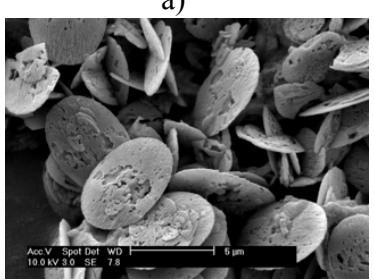

c)

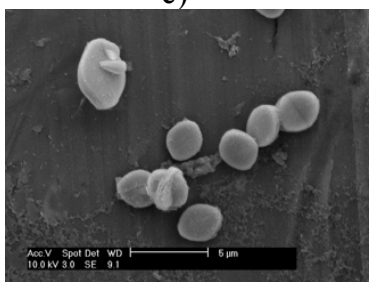

e)

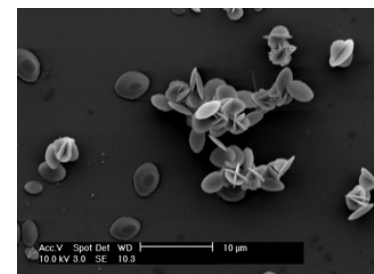

b)

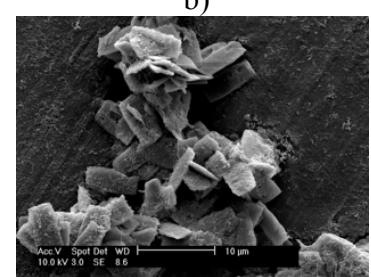

d)

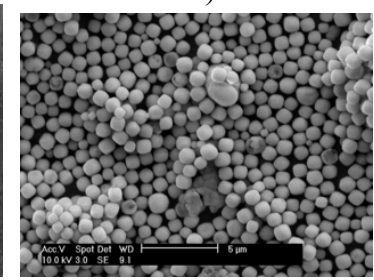

f)
Figure 2. Barium sulfate particles obtained in the presence of a) Control - no additives b) $0.017 \mathrm{mM} \mathrm{NTMP} \mathrm{c)} 0.021 \mathrm{mM}$ NDMPA d) $0.044 \mathrm{mM}$ NMPDA e) $0.026 \mathrm{mM}$ NTA and f) 0.078 mM NTA.

XRD obtained on the particles formed in the presence of 0.078 mM NTA showed no significant line broadening when compared to the control sample (see appendix). Thus, these particles are not formed by the agglomeration of smaller particles as is often found for spherical barium sulfate particles ${ }^{5}$. This in turn suggests that the morphology control is due to some surface adsorption process and given the uniformity of the particles further suggests that this adsorption is equal on all faces. Also, note the monodisperse nature of the particles, once again implying a uniform surface interaction.

The NTA then is said to behave, using the term coined by Coveney et al. ${ }^{16}$, as a "universal face-binding agent". The concentration used here at $0.078 \mathrm{mM}$ is a similar concentration found to be required to form rounded barium sulfate particles by Coveney et al. ${ }^{16} \quad(\sim 0.09 \quad \mathrm{mM}$ of a macrocyclic aminomethylphosphonate). Thermal analysis was performed (see appendix), and it appears that roughly $2 \%$ of the solids by weight is organic which correlates to $3 \%$ of the added organic being adsorbed or incorporated by the barium sulfate when added at $0.078 \mathrm{mM}$.

\section{Discussion}

Carboxylate polymer molecules are known to inhibit barium sulfate precipitation ${ }^{14}$ presumably due to the number of carboxylate-surface interactions but small carboxylate molecules are not recognised as inhibiting the precipitation of barium sulfate at low concentrations or moderate $\mathrm{pHs}$ (morphology effects of small carboxylates have been reported at high $\mathrm{pH}$ and attributed to solution complexation ${ }^{1,15}$ ). It is clear that, whatever the effect of the tricarboxylate, it must differ in some respect from the interactions of the other molecules. Thus, the tricarboxylate molecule appears to be unique despite it being an end member of a systematically altered group. It is also possible that the triphosphonate and the tricarboxylate inhibit via different mechanisms resulting in significantly different morphologies.

Monodispersity could be due to nucleation promotion, however, the conductivity measurements clearly also point to growth inhibition. This suggests that the NTA is able to bind to sites on all faces. Which surface sites and how the NTA binds to them is yet to be determined. Further experimental work and an upcoming molecular modeling study on this system will hopefully shed some light on what factors govern inhibition efficacy and morphology modification. It is also interesting to note that the additives which show inhibition also alter morphology but those that alter morphology do not necessarily inhibit crystallization.

\section{Notes and references}

* based on complexation constants for calcium ions since complexation constants for barium were not available for all the compounds.

1. Uchida, M.; Sue, A.; Yoshioka, T.; Okuwaki, A., J. Mater. Sci. Lett., 2000, 19, 1373-1374.

2. Stávek, J.; Sípek, M.; Hirasawa, I.; Toyokura, K., Chem. Mater., 1992, 4, 545-555.

3. Weissbuch, I.; Leiserowitz, L.; Lahav, M., in Crystallization Technology Handbook, A. Mersmann (eds), 1995, Marcel Dekker Inc., New York, Chap 6, 401-57.

4. Qi, L.; Cölfen, H.; Antonietti, M., Angew. Chem. Int. Ed., 2000, 39, 604-607.

5. Li, M.; Mann, S. Langmuir, 2000, 16, 7088-94

6. Bromley, L. A.; Cottier, D.; Davey, R. J.; Dobbs, B.; Smith, S.; Heywood, B. R., Langmuir, 1993, 9, 3594-9.

7. Black, S. N.; Bromley, L. A.; Cottler, D.; Davey, R. J.; Dobbs, B.; Rout, J. E., J. Chem. Soc. Faraday Trans, 1991, 87, 3409-3414.

8. Breen, P. J.; Downs, H. H.; Diel, B. N., Spec. Publ. - R. Soc. Chem., 1991, 97, 186-98.

9. Davey, R. J.; Black, S. N.; Bromley, L. A.; Cottier, D.; Dobbs, B.; Rout, J. E., Nature, 1991, 353, 549-50.

10. Benton, W. J.; Collins, I. R.; Grimsey, I. M.; Parkinson, G. M.; Rodger, S. A., Faraday Discussions, 1993, 95, 281-297.

11. van der Leeden, M. C.; van Rosmalen, G. M., J. Colloid Interface Sci., 1995, 171, 142-9.

12. Van der Leeden, M. C. (Doctoral Thesis), The role of polyelectrolytes in barium sulfate precipitation; Technical University of Delft: Delft, 1991.

13. van der Leeden, M. C.; van Rosmalen, G. M., Spec. Publ. - R. Soc. Chem., 1988, 67 (Chem. Oil Ind.), 68-86. 
14. Ross, R. J.; Low, K. C.; Shannon, J. E., Mater. Perform., 1997, 36, 53-57.

15. Uchida, M.; Sue, A.; Yoshioka, T.; Okuwaki, A., Cryst. Eng. Comm., 2001, 5, 1-6.

16. Coveney, P. V.; Davey, R. J.; Griffin, J. L. W.; He, Y.; Hamlin, J. D.; Stackhouse, S.; Whiting, A., J. Am. Chem. Soc., 2000, 122, 11557-

11558.

17. Kazmierczak, T.F.; Tomson M.B.; Nancollas, G.H., J. Phys. Chem, 1982, 86, 103-107.

18. Wheeler, A.P.; Low C.K.; Sikes, C.S., 1990 "CaCO3 Crystal-

Binding Properties of Peptides and Their Influence on Crystal Growth",

in Surface Reactive Peptides and Polymers: Discovery and

Commercialization, C.S. Sikes and A.P. Wheeler (eds.) pp. 72-84, ACS

Books, Washington

19. Martell, A. E.; Smith, R. M., "Critical Stability Constants" 1974-

1977, Plenum Press, New York.

\section{Appendix}

Table A1. Observed rates of barium sulfate desuperaturation in the presence of the various additives (linear region of curve).

\begin{tabular}{|c|c|c|}
\hline Additive & $\begin{array}{l}\text { Concentration } \\
(\mathrm{ppm})\end{array}$ & $\begin{array}{l}\text { Observed } \\
\text { desupersaturation } \\
\text { rate }\left(-1 \times 10^{-5} \mathrm{mS} / \mathrm{s}\right)\end{array}$ \\
\hline None & N/A & 3.34 \\
\hline \multirow[t]{3}{*}{ NTMP } & $2.0 \quad(0.007 \mathrm{mM})$ & 2.14 \\
\hline & $5.0(0.017 \mathrm{mM})$ & 1.66 \\
\hline & $10.0(0.034 \mathrm{mM})$ & 1.00 \\
\hline \multirow[t]{3}{*}{ NDMPA } & $5.0 \quad(0.021 \mathrm{mM})$ & 2.82 \\
\hline & $10.0(0.042 \mathrm{mM})$ & 2.99 \\
\hline & $15.0(0.063 \mathrm{mM})$ & 1.72 \\
\hline \multirow[t]{3}{*}{ NMPDA } & $5.0 \quad(0.022 \mathrm{mM})$ & 3.45 \\
\hline & $10.0(0.044 \mathrm{mM})$ & 3.45 \\
\hline & $15.0(0.066 \mathrm{mM})$ & 4.00 \\
\hline \multirow[t]{3}{*}{ NTA } & $5.0 \quad(0.026 \mathrm{mM})$ & 3.85 \\
\hline & $10.0(0.052 \mathrm{mM})$ & 2.34 \\
\hline & $15.0(0.078 \mathrm{mM})$ & 1.33 \\
\hline
\end{tabular}

Figure A1. XRD traces of barium sulfate control and barium sulfate produced in the presence of $15 \mathrm{ppm}$ NTA. The peak marked with a dot is an unknown. (The two spectra have been offset for clarity)

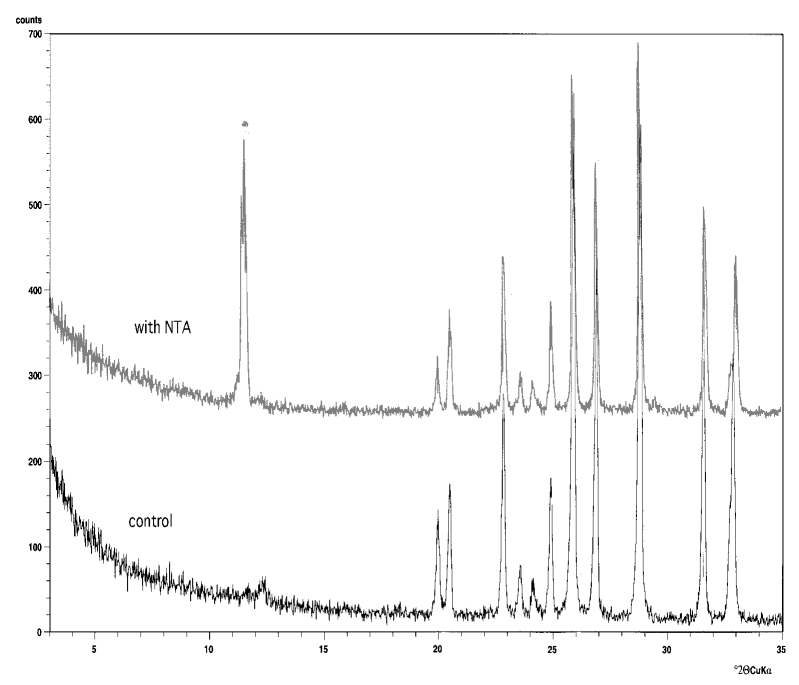

Figure A2. TGA traces of barium sulfate control and barium sulfate produced in the presence of $15 \mathrm{ppm}$ NTA.

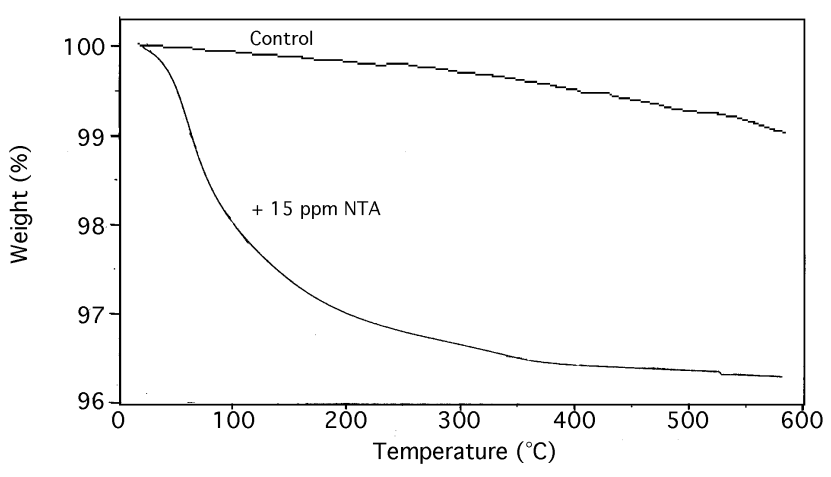

